Sammlung Metzler

Band 272 
Bernhard Sowinski

\section{Heinrich Böll}

Verlag J. B. Metzler Stuttgart - Weimar 
Die Deutsche Bibliothek - CIP-Einheitsaufnahme

Sowinski, Bernhard:

Heinrich Böll / Bernhard Sowinksi.

- Stuttgart: Weimar: Metzler, 1993

(Sammlung Metzler; Bd. 272)

ISBN 978-3-476-10272-0

NE: GT

\author{
ISSN 05583667 \\ ISBN 978-3-476-10272-0 \\ ISBN 978-3-476-03972-9 (eBook) \\ DOI 10.1007/978-3-476-03972-9
}

SM 272

Dieses Werk einschließlich aller seiner Teile ist urheberrechtlich geschützt. Jede Verwertung außerhalb der engen Grenzen des Urheberrechtsgesetzes ist ohne Zustimmung des Verlages unzulässig und strafbar. Das gilt insbesondere für Vervielfältigungen, Übersetzungen, Mikroverfilmungen und die Einspeicherung und Verarbeitung in elektronischen Systemen.

(C) 1993 Springer-Verlag GmbH Deutschland

Ursprünglich erschienen bei J.B. Metzlersche Verlagsbuchhandlung und Carl Ernst Poeschel Verlag GmbH in Stuttgart 1993 


\section{Inhaltsverzeichnis}

Vorbemerkung $\ldots \ldots \ldots \ldots \ldots \ldots$ VII

1. Angaben zu Leben und Werk . . . . . . . . . 1

1.1 Zur Biographie Heinrich Bölls . . . . . . . . . . 1

Kindheit und Jugend - Kriegszeit - Nachkriegszeit - Bölls frühe Tätigkeit als Schriftsteller - Die ersten Romane und größeren Erzählungen - Zunahme der Gesellschafts- und Zeitkritik - Beginn politischer Aktivitäten - Auseinandersetzung mit der Springer-Presse und dem Terrorismus - Teilnahme an öffentlichen Protesten - Die letzten Lebensjahre

1.2 Ehrungen Heinrich Bölls . . . . . . . . . . . 28

2. Bölls literarisches Werk . . . . . . . . . . . 29

2.1 Autobiographische Texte . . . . . . . . . . 29

2.2 Bölls Kurzgeschichten und kürzere Erzählungen . . . 33

2.2.1 Kriegserzählungen. . . . . . . . . . . . 34

2.2.2 Kurzgeschichten aus der Nachkriegszeit. . . . . 38

2.2.3 Moralisch und religiös bestimmte Texte . . . . . 41

2.2.4 Ironische und satirische Erzählungen . . . . . . 43

2.3 Größere Erzählungen und Romane . . . . . . . . . 49

Der Zug war pünktlich - Wo warst du, Adam? - Nicht nur zur Weihnachtszeit - Und sagte kein einziges Wort - Haus ohne Hüter - Das Brot der frühen Jahre - Doktor Murkes gesammeltes Schweigen - Im Tal der donnernden Hufe - Billard um halbzehn - Ansichten eines Clowns - Entfernung von der Truppe - Ende einer Dienstfahrt - Gruppenbild mit Dame - Die verlorene Ehre der Katharina Blum - Berichte zur Gesinnungslage der Nation - Fürsorgliche Belagerung Das Vermächtnis - Die Verwundung - Frauen vor Flußlandschaft - Der General stand auf einem Hügel - Der Engel schwieg

2.4 Hörspiele, Fernsehtexte, Theaterstücke . . . . . . . . 94

2.5 Gedichte . . . . . . . . . . . . . 105

3. Reiseberichte und Ortsbeschreibungen(Auswahl) 113

4. Essays, Reden, Rezensionen (Auswahl). . . . . . 118 
5. Interviews und Gespräche (Auswahl) . . . . . 126

6. Thematische Hinweise . . . . . . . . . . 131

6.1 Böll, Köln und das Rheinland. . . . . . . . . . . . 131

6.2 Bölls Stellung zu Kirche und Christentum . . . . . . 134

6.3 Bölls Verhältnis zu Staat und Gesellschaft . . . . . . . 138

6.4 Poetologische Positionen Bölls . . . . . . . . . . . . 145

6.5 Zur Entwicklung der Form in Bölls Epik . . . . . . . 148

7. Aspekte der Böll-Forschung. . . . . . . . . . . 152

7.1 Schwerpunkte der bisherigen Böll-Forschung. . . . . 152

7.2 Forschungsprojekte und Forschungsstätten . . . . . 158

8. Bibliographie . . . . . . . . . . . 161

8.1 Primärtexte mit Literaturhinweisen (außer größere Erzählungen und Romane) . . . . . . 161

8.2 Sekundärliteratur . . . . . . . . . . . . 176

Abkürzungsverzeichnis. . . . . . . . . . . . . 212

Werkregister . . . . . . . . . . . . . 215

Namenregister . . . . . . . . . . . . . 221

Angaben zum Autor . . . . . . . . . . . . . 225 


\section{Vorbemerkung}

Die Erforschung des Werkes Heinrich Bölls, dessen Würdigung zu Lebzeiten des streitbaren Autors mitunter durch subjektive Wertungen beeinträchtigt worden war, ist nach seinem Tod (1985) in ein neues Stadium getreten und bedarf noch mancher neuer Einsichten. Gemäß der Zielsetzung der »Sammlung Metzler « kommt es in diesem Buch darauf an, "Realien zur Literatur « zu vermitteln, um so die Kenntnis des Autors und seiner Texte in Studium, Lehre und Forschung zu fördern.

Dementsprechend beschränke ich mich hier auf die Darbietung biographischer Fakten zu Leben und Werk des Dichters, von Inhaltsübersichten (als Erinnerungshilfen, nicht als Lektüreersatz), von Interpretationsansätzen und Forschungshinweisen zu den dichterischen Texten sowie auf Übersichten zum übrigen literarischen Schaffen des Literatur-Nobelpreisträgers von 1972. Auf literaturkritische Wertungen, wie sie in den zahlreichen Rezensionen nach Erscheinen der Texte teilweise recht kontrovers ausfielen, wurde hier im allgemeinen verzichtet. Literaturhinweise nach der Besprechung der Texte beschränken sich auf Verfassernamen und Erscheinungsjahr. Die vollständigen Literaturangaben finden sich im alphabetisch geordneten Literaturverzeichnis am Schluß des Bandes. Auf ein Verzeichnis sämtlicher Werke Bölls wurde angesichts der verschiedenen Textsammlungen (u.a. zehnbändige Werkausgabe von Bernd Balzer (Hg.) und der zahlreichen Einzelausgaben als dtv-Taschenbücher) verzichtet.

Allen denen, die mir bei der Ermittlung und Darbietung der Angaben geholfen haben, danke ich herzlich.

Köln, im August 1992

B. S. 